\title{
What will be the risk-free rate and benchmark yield curve following European monetary union?
}

Article

Accepted Version

Brooks, C. and Skinner, F. (2000) What will be the risk-free rate and benchmark yield curve following European monetary union? Applied Financial Economics, 10 (1). pp. 59-69. ISSN 0960-3107 doi: https://doi.org/10.1080/096031000331932 Available at https://centaur.reading.ac.uk/35966/

It is advisable to refer to the publisher's version if you intend to cite from the work. See Guidance on citing.

Published version at: http://dx.doi.org/10.1080/096031000331932

To link to this article DOI: http://dx.doi.org/10.1080/096031000331932

Publisher: Taylor and Francis

All outputs in CentAUR are protected by Intellectual Property Rights law, including copyright law. Copyright and IPR is retained by the creators or other copyright holders. Terms and conditions for use of this material are defined in the End User Agreement.

$\underline{\text { www.reading.ac.uk/centaur }}$ 
Central Archive at the University of Reading

Reading's research outputs online 
This is an Author's Accepted Manuscript of an article published in Applied Financial Economics (2000) [copyright Taylor \& Francis], available online at: www.tandfonline.com/10.1080/096031000331932 


\title{
What Will be the Risk-Free Rate and Benchmark Yield Curve following European Monetary Union?
}

Chris Brooks and Frank Skinner ${ }^{1}$

March 1998

\begin{abstract}
Using a linear factor model, we study the behavior of French, German, Italian and British sovereign yield curves in the run up to EMU. This allows us to determine which of these yield curves might best approximate a benchmark yield curve post EMU. We find that the best approximation for the risk free yield is the UK three month T-bill yield, followed by the German three month T-bill yield. As no one sovereign yield curve dominates all others, we find that a composite yield curve, consisting of French, Italian and UK bonds at different maturity points along the yield curve should be the benchmark post EMU.
\end{abstract}

J.E.L. Classifications: C22, C53, F31

Keywords: European monetary union, sovereign yield curve, risk free rate

\footnotetext{
1 The authors are grateful to Con Keating for useful comments, Peter Jones for providing key data, and to the European Bond Commission for financial assistance. The usual disclaimer applies. The authors are both members of the ISMA Centre, Dept of Economics, University of Reading, Whiteknights Park, PO Box 242, Reading, RG6 6BA.
} 


\section{Introduction: Challenges Posed by EMU for the European Debt Market}

Currently, sovereign zero coupon yield curves are used as benchmarks to judge the appropriate yields of bonds denominated in national currencies. These benchmarks are used as the underlying base yield where a spread, determined by such factors as relative credit risk, is added to make up the yield on similar duration corporate debt. This relative pricing technique appears to be the market standard, as it is difficult to find instances where a corporate debt security has a lower yield than its corresponding sovereign, and where such instances can be found, they can be attributed to poor quality information. More obscurely, zero coupon sovereign yield curves are used to price national currency denominated interest rate derivatives, such as interest rate caps, by "calibrating" the assumed stochastic process to the visible current sovereign yield curve.

At the very short end of sovereign yield curves is a special benchmark rate termed the "risk free" rate. It is special as it is a heavily used input into asset pricing models. For example, the stochastic process of this "risk free rate" is an input in all stochastic interest rate pricing models, both "arbitrage free" and "equilibrium", that are used to price interest rate derivatives and bonds with embedded options like callable bonds. Also, this "risk free" rate is the starting point to "bootstrap" the construction of the sovereign zero coupon yield curve that are later used as benchmarks.

After EMU, there will be no "national" currency, so the choice of which sovereign yield curve to use as the benchmark is not obvious. This can lead to serious pricing errors. For instance, one market participant using the German yield curve will generate different values for say, an interest rate cap, than another using the French yield curve. The purpose of this paper is to consider, after EMU, what will be the benchmark yield curve?

The remainder of this paper is organized as follows. In the next section, we describe the criteria used to choose the post EMU benchmark yield curve. In section 3, details of the pricing model are discussed. This section is divided into four parts. First we describe the data, and then we present the empirical results in two parts. We first estimate the risk free rate since it plays a special role and requires a slightly different 
estimation procedure. Then we examine longer term rates at the 1-3, 3-5, 5-7, 7-10 and 10 plus year maturity ranges for all four sovereigns. The fourth section summarises and offers some conclusions.

\section{Methodology}

By what criteria shall we chose the appropriate benchmark yield curve post EMU? The answer to this question lies in the purpose of a benchmark. As noted above, the sovereign yield curve is used as the base upon which all other debt securities are to be priced by adding appropriate risk premiums to the benchmark. Therefore the appropriate benchmark will be the one with the lowest overall level of risk.

We employ a multiple linear factor model to measure risk sensitivities. Following Elton, Gruber and Blake (1995) and Stone (1991), we augment an arbitrage pricing theory (APT) model with unexpected changes in fundamental factors. We choose fundamental factors have been shown to be important determinants of corporate bond yields by Elton, Gruber and Blake (1995) and those than have been shown by Cantor and Packer (1996) to be statistically significant determinants of sovereign bond ratings. We will also examine unexpected changes in foreign exchange rates as this factor has been mentioned by Hogeweg (1996) as a potential source of a bond risk premium. These variables are broadly consistent with the fundamental factors found to be significant by Rockerbie (1993) in explaining yield spreads of private loan guaranteed by sovereigns and by Cosset, Daouas, Kettani, and Oral (1993), and Cosset and Roy (1991) who examined the debt of a large group of industrialized and less developed sovereigns. Estimates of this model will reveal which of these factors, along with world bond and stock returns, are priced by the market as important sources of risk.

Therefore we will test for seven market determined risk factors, made up of two relative pricing and five fundamental economic factors. The relative pricing factors are the covariance with world equity market returns and the covariance with world bond market returns. The fundamental factors are unexpected changes in: inflation, GDP, fiscal balance, per capita income and exchange rates, all of which reflect a country's ability to pay its debt costs. 
The rationale for including these fundamental factors are as follows. Unanticipated inflation is risky for bond holders as it reduces the real value of cash flows, and may also point to the government monetising debt rather than raising taxes to finance expenditures. Increases in real GDP indicate an increase in the financial strength of a country's economy and therefore an increase in the sovereign's ability to service debts. An increasing fiscal surplus (or a deficit reduction) indicates that government debts are decreasing and therefore that default on existing debt is less likely ${ }^{2}$. Rises in per capita incomes imply a stronger tax base and therefore that the government will find it easier to raise finances to service or repay debts. Alternatively, rises in per capita income may foreshadow higher inflation rates. Finally, unanticipated improvements in exchange rates will improve the international purchasing power of cash flows denominated in a domestic currency and increase its value for debt holders.

The fundamental proxies that are actually used as independent variables in the regressions are calculated as the one period changes in consumer inflation, real GDP growth in percent, fiscal balance relative to GDP, per capita GDP converted into US dollars and three month forward exchange rates. The first four fundamental variables are the same variables used by Cantor and Packer (1996). However, the pricing model we use to estimate the risk sensitivities demands unexpected changes in these fundamental factors (rather than the whole changes or the levels of these variables), so we use the one period ahead changes to capture the unexpected nature of the fundamental risk factors. In some cases, we are able to refine the proportion of these one period ahead changes that was anticipated and that proportion which was unanticipated through use of ARIMA modeling.

When examining the "risk free rate", we include the expected rate of consumer inflation to avoid a missing variable bias since there is no doubt that a large fraction of the realized return from holding short term instruments is related to the level of inflation. When examining longer term sovereign securities, we include the current rate of inflation to proxy the market's view of the credibility of the sovereign's

\footnotetext{
${ }^{2}$ Alternatively, an increasing fiscal balance may indicate a tightening of fiscal policy that may later lead to a recession and increases in credit risk.
} 
monetary authority. The motivation is that the reaction of bond markets to the expected short term rate of inflation suggests the market's views of the likely response of the monetary authority to the current rate of inflation. Therefore each model includes eight independent variables.

We evaluate the French, German, Italian and United Kingdom sovereign yield curves as these four sovereign yield curves are the most likely candidates for the benchmark yield curve post EMU. We believe they are the most likely candidates as they are all G7 economies rated triple A with a stable outlook by Standard and Poors with the exception of Italy (which at AA+ is only one rating notch lower), and all are rated triple A by Moodys. For each sovereign yield curve, we measure market-assessed risk for six points along the yield curve: one year or less, 1-3 years, 3-5 years, 5-7 years, 710 years and 10 years and above. Our choice of the benchmark would be that sovereign yield at each point along the yield curve that has historically the lowest composite risk premium and lowest composite risk sensitivity as measured by the bond market. Our methodology does not dictate that one sovereign dominates as the benchmark all along the yield curve. It is possible that different sovereigns may form the benchmark yield at different points along the yield curve.

\subsection{The Linear Factor Model}

Following Chen, Roll and Ross (1986) we hypothesize that actual returns from sovereign bond investments can be decomposed into two parts, one expected and another unexpected. While the expected returns are generated from the expected values of systematic factors only, the unexpected returns are generated by unexpected values of systematic and unsystematic factors. The systematic factors consist of tradable portfolios (bond and equity returns) and fundamental factors (inflation, GDP, fiscal balance, per capita income and exchange rates). This model is represented as

$r_{i t}=\mathrm{E}\left[r_{i}\right]+\sum_{j=1}^{J} B_{i j}\left(R_{j t}-E\left[R_{j}\right]\right)+\sum_{k=1}^{K} \gamma_{\imath \kappa} g_{k t}+\varepsilon_{\imath \tau}$

The left hand side variable represents actual returns. The first term on the right hand side of (1) represents the expected return, and the next three terms represent that portion of the actual return that was unexpected. The second term on the right hand side represents that portion of the actual return due to unexpected realizations from the tradable portfolios, the third term that portion of actual return due to unexpected 
realizations from the fundamental factors (or untradeable portfolios) and the last term that portion of actual return due to realizations of unsystematic risk. In detail, the notation represents the following:

$r_{i t}$ is the realized return on asset $i$ at time $t$, where asset $i=1$ is $1-3$ year, $i=2$ is

3-5 year, $i=3$ is 5-7 year, $i=4$ is 7-10 year, and $i=5$ is 10 year plus bond yields.

There are four sets of equations to be studied, one each for France,

Germany, Italy and the United Kingdom.

$\mathrm{E}\left[r_{i}\right]$ is the expected return on asset $i$ since $\mathrm{E}[\cdot]$ represents the expectation of the term in square brackets.

$B_{i j}$ is the sensitivity of asset $i$ to unexpected realizations in the returns on tradable portfolio $j$, where $j=1$ is the world stock market index and $j=2$ is the world bond market index.

$R_{j t}$ is the actual return on tradable portfolio $j$ at time $t$, and as above, $\mathrm{E}\left[R_{j}\right]$ is the expected return on tradable portfolio $j$.

$\gamma_{i k}$ is the sensitivity of asset $i$ to unexpected changes in the $k^{\text {th }}$ fundamental factor, where $k=1$ is inflation, $k=2$ is GDP, $k=3$ is fiscal balance, $k=4$ is per capita income and $k=5$ is exchange rates.

$g_{k t}$ is the unexpected change in the $k^{\text {th }}$ fundamental factor.

$\varepsilon_{i t}$ is the realized return due to unsystematic factors.

From here we derive our linear factor model in exactly the same way as Elton, Gruber and Blake (1995). Initially, we know from APT that the appropriate expression for the expected return that follows from our formulation of realized returns in (1) is

$\mathrm{E}\left[r_{i}\right]=\lambda_{0}+\sum_{j=1}^{J} B_{i j} \lambda_{\mathrm{j}}+\sum_{\mathrm{k}=1}^{\mathrm{K}} \gamma_{\mathrm{ik}} \lambda_{\mathrm{k}}$

where $\lambda_{0}$ is the return from the risk free rate and the $\lambda_{\mathrm{s}}$ are the risk premiums, $\lambda_{j} \mathrm{~s}$ are the risk premiums for tradable assets and $\lambda_{k} \mathrm{~s}$ are the risk premiums for fundamental factors.

Since the risk premiums for tradable assets are $\lambda_{j}=\mathrm{E}\left[r_{j}\right]-\lambda_{0}$, and $\lambda_{0}$ is the risk free rate, then we can substitute this expression into (2). This yields 
$\mathrm{E}\left[r_{i}\right]=R_{f}+\sum_{j=1}^{J} B_{i j}\left(\mathrm{E}\left[R_{j}\right]-R_{f}\right)+\sum_{\mathrm{k}=1}^{\mathrm{K}} \gamma_{\mathrm{ik}} \lambda_{\mathrm{k}}$

We can substitute (3) into (1) to cancel out those terms that depend upon expectations, which is necessary since expectations are unobservable. We are then left with a model whose terms are all observable. Therefore all the risk premiums can be estimated.

Replacing the first term of (1) with (3) we have

$\mathrm{r}_{i \mathrm{t}}=R_{f}+\sum_{j=1}^{J} B_{i j}\left(\mathrm{E}\left[R_{j}\right]-R_{f}\right)+\sum_{\mathrm{k}=1}^{\mathrm{K}} \gamma_{\mathrm{ik}} \lambda_{\mathrm{k}}+\sum_{j=1}^{J} B_{i j}\left(R_{j t}-E\left[R_{j}\right]\right)+\sum_{k=1}^{K} \gamma_{\iota K} g_{k t}+\varepsilon_{\imath \tau}$

We can see that the $E[\cdot]$ s cancel. We then rearrange terms slightly to obtain (4), the first model that we can estimate.

$r_{i t}=R_{f}+\sum_{j=1}^{J} B_{i j}\left(R_{j t}-R_{f}\right)+\sum_{\mathrm{k}=1}^{\mathrm{K}} \gamma_{\mathrm{ik}} \lambda_{\mathrm{k}}+\sum_{k=1}^{K} \gamma_{\mathrm{ik}} g_{k t}+\varepsilon_{\mathrm{t}}$

However, there still is a problem with (4). Notice that the three sets of independent variables are $\left(R_{j t} R_{f}\right), \lambda_{k}, g_{k t}$. However, our objective is to estimate the $\lambda \mathrm{s}$. In effect, we have an equation of with three sets of "unknowns", $B_{i j}, \gamma_{i k}$, and $\lambda_{k}$ and only two sets of observable independent variables, the risk premium on tradable portfolios, $\left(R_{j t}-R_{f}\right)$ and the unexpected changes in fundamental factors, $g_{k t}$. We fix this problem by subtracting $R_{f}$ from both sides of (4) to obtain (5), our final model.

$r_{i t}-R_{f}=\sum_{\mathrm{k}=1}^{\mathrm{K}} \gamma_{\mathrm{ik}} \lambda_{\mathrm{k}}+\sum_{j=1}^{J} B_{i j}\left(R_{j t}-R_{f}\right)+\sum_{k=1}^{K} \gamma_{\mathrm{ik}} g_{k t}+\varepsilon_{\mathrm{t}}$

The difference here is that we have cleared the constant to be $\sum_{\mathrm{k}=1}^{\mathrm{K}} \gamma_{\mathrm{ik}} \lambda_{\mathrm{k}}$, so we can estimate $\lambda_{k}$ iteratively. This nonlinear technique will estimate $\sum_{\mathrm{k}=1}^{\mathrm{K}} \gamma_{\mathrm{ik}} \lambda_{\mathrm{k}}$ as a constant and estimate the slope $\gamma_{i k}$ on the variable $g_{k t}$ during the "first pass" and then reestimate the constant in a "second pass" using the first pass estimate of the slope $\gamma_{i k}$ to obtain a more accurate estimate of the interactive term $\lambda_{k}$. The resulting standard errors are also asymptotically valid under the standard classical assumptions. This is the model we will use to estimate the risk factors on the market returns $B_{i j}$ and the risk premiums on fundamental factors $\lambda_{k}$.

\section{Empirical Analysis}


In this section, we explore the responsiveness of the French, German, Italian and UK yield curve to changes in equity and bond market returns and unexpected changes in fundamental factors. The ideal benchmark yield curve should have no significant market assessed risk premium on fundamental factors, that is an expected penalty premium based on expected changes in the value of fundamental factors, nor should it respond to unexpected changes in the fundamental factors and market returns. Amongst those yield curves having no significant fundamental factor risk premiums, the benchmark yield would be the yield that has the smallest significant sensitivities (betas) to changes in market returns and unexpected changes in the fundamental factors.

\subsection{Data}

Our model (5) requires a historical time series of observations of all the independent and dependent variables. For the dependent variables, we chose the EFFAS total return tracker index for French, German, Italian and UK bond indices for 1-3, 3-5, 5-7, 7-10 and 10 plus years to maturity 3 . This monthly data series runs from July 1993 to June 1997. While this data series yields a modest sample size of 48 data points, this is the most interesting time interval as it incorporates the time that the market was adjusting to information concerning the likelihood of and benefits from EMU participation. As candidates for the risk free rate, we use three month T-bill rates for France, Italy and the UK obtained from Datastream. As no comparable three month T-bill rate is available for Germany, we instead employ a one year T-bill rate that was available from Bloomberg. The original source of this risk free rate data is the International Monetary Funds International Financial Statistics.

Historic time series returns for the world bond market and the world stock market returns are obtained from Datastream as is the information used to construct proxies for unexpected changes in the five fundamental factors. We used the Financial Times Actuaries world stock index and the JP Morgan world government bond index as proxies for the world stock and bond markets respectively. We collected data for the

\footnotetext{
3 Ideally, we would like to use the liquid index since bonds underlying this index trade more frequently and so bond prices are more indicative of market conditions. However, Italy's liquid index begins later in the sample period, so we judged it better to use the longer, but somewhat less liquid tracker index for all benchmark yield curves to ensure that all candidates are placed on an equal footing.
} 
risk free rate, world bond and equity returns and fundamental factor series which runs from January 1986 to December 1996, a total of 132 monthly observations.

To capture the essence of the unexpected nature of changes in the fundamental factors, we use the one period ahead change in the variable in question. This assumes that investors have no forecasting ability beyond the current period and that the current value of the variable is next period's expected value. The use of a random walk-type forecasting equation is well-grounded in rational expectations theory. No doubt survey data would be better in formulating the expected return next period, but such information was only available for France. To ensure that our results are comparable across countries, we consider it preferable to use equivalent data that is available for all four countries in question.

However, in contrast to the long data series that is available for proxies for the risk free rate, we are forced to use a shorter data series when examining longer term yields since the EFFAS bond yield indices commenced in July 1993. When examining the independent variables for this shorter time interval, we found it possible to refine what portion of these one period ahead changes can be anticipated through use of BoxJenkins (1976) ARIMA modeling 4 . The idea is that at time $t$, investors form expectations about the change in the value of say, inflation, is to be in one period's time. This means that next period's realised change in inflation can be decomposed into two portions, one part expected, one part unexpected. If we can somehow model what portion of the next period's actual rate of inflation was expected, then the difference between the actual and expected rates of inflation would be the unexpected changes in the rate of inflation.

We assume that investors can spot any regular linear pattern in the time series of changes in the rate of inflation and use that information to forecast future inflation rate changes. Therefore we use Box-Jenkins (1976) to model the historic patterns in the changes in inflation as of time $t$, and then use this pattern to project what the anticipated rate of inflation is to be at time $t+1$. Therefore the unanticipated rate of 
inflation would be the actual $t+1$ rate of inflation less the anticipated rate of inflation for time $t+1$ projected last period $(t)$ by the ARIMA model. We construct a time series of unanticipated changes for all fundamental factors in this way.

\subsection{The Risk Free Rate}

It is conventional to assume that the risk free rate is the short term discount yield on direct Sovereign obligations. However, we are attempting to determine which one of four candidates is the "best" proxy for the risk free rate and $r_{i t}$ in (5) is the realized holding period return on short term discount sovereign obligations. Therefore we cannot assume that the risk free rate exists and subtract it from $r_{i t}$ as well. This means we cannot estimate (5) in this instance, and instead we estimate (4).

We cannot estimate risk premiums from (4) as the constant consists of three parameters, $\gamma_{i k}, \lambda_{k}$ and the theoretical $R_{f}$ rather than two, $\gamma_{i k}$ and $\lambda_{k}$, in (5). Non linear estimation methods can only iteratively solve for two parameters as only one other parameter $\gamma_{i k}$, can be independently estimated in the first pass. By estimating (4), we measure response coefficients on the seven risk factors and the current rate of consumer inflation. The idea here is that the actual return from investing in a true risk free asset should be independent of risk factors. If the rate is truly risk free, we should observe statistically insignificant coefficients on all risk factors except for the expected inflation variable. The latter should be significant since investors should automatically require higher yields if they know that inflation will rise in order to preserve the real purchasing power of their cash flows.

If the candidate risk free asset is in fact not risk free, then we would observe statistically significant response coefficients on some or all of the seven risk factors. We expect the bond factor betas to be negative, but the equity factor betas could be positive or negative. The latter result comes from Jarrow (1978) who first derived "equity factor betas" which can be estimated by regressing bond yields against an equity market index. This "equity factor beta" can be expressed as (see Rao, 1982)

$$
B=-D R_{b}\left[\operatorname{Cov}\left(R_{m}, R_{b}\right) / \operatorname{Var}\left(R_{m}\right)\right]
$$

\footnotetext{
${ }^{4}$ ARIMA models were also estimated for the independent variables in the risk free regressions, but these yielded no significant coefficient estimates in the Box Jenkins regressions and hence the actual
} 
Where $D$ is duration of the bond, and $R_{m}$ and $R_{b}$ are the equity market return and bond yield respectively. As Rao (1982) observes, there is no reason why the covariance between the market returns and the bond yields cannot be positive, so this "equity factor beta" can be negative as well as positive.

Unexpected fiscal balance and income response coefficients can be positive or negative. A positive unexpected income beta can result from underutilized capacity, so unexpected increases in income will lead to higher real incomes and improvements in the sovereign's ability to service debt. However, a negative unexpected income beta might indicate that unexpected income increases are inflationary since existing capacity is fully utilized, and therefore reduces real bond returns. Similarly, an increase in per capita fiscal balance represents a reduction in sovereign debt so we would expect a positive coefficient. But a negative coefficient may occur because an improvement in the fiscal balance also represents a tightening of fiscal policy raising the possibility of a future recession.

The signs of expected inflation, unanticipated inflation and real GDP growth coefficients are clear, however. Holding period returns on short term debt should be positively associated with the current expected rate of inflation as investors demand protection from inflation expected through their holding period. Unanticipated inflation reduces the real return of all bond investments so the response coefficient should be negative, whereas unanticipated real GDP growth improves the sovereign's ability to service its debt so this coefficient should be positive.

For unexpected changes in the forward exchange rate, the sign will depend upon how the exchange rate is quoted. For France, Germany and Italy, the forward exchange rate is in terms of domestic currency to US dollars, so a rise in the exchange rate represents a deterioration in the value of the domestic currency. Therefore we expect a negative coefficient. In the case of the UK, the forward exchange rate is quoted in terms of US dollars per pound, so a rise in the exchange rate represents an improvement in the value of the pound. In this case we expect a positive coefficient.

values of the variables were used in the risk free rate regressions. 
We estimated (4) for French, German, Italian and UK short term Treasury holding period returns on a monthly basis from January 1986 to December 1996. We subjected the regression results to a battery of diagnostic tools for checking the validity of the standard classical assumptions. The tests used were Engle's (1982) test for autoregressive conditional heteroscedasticity, the Ljung-Box (1978) test for autocorrelation, the Bera Jarque (1981) normality test, the augmented Dickey Fuller (ADF) test for unit root non-stationarity (Dickey and Fuller, 1979; Fuller, 1976), and Ramsey's (1969) RESET test which is a portmanteau test for the appropriateness or otherwise of the linear functional form used in the regressions. The tests revealed problems with both autocorrelation and heteroscedasticity which implies that the standard errors of the coefficient estimates might be wrong. So long as we have the "correct" model (and in particular, no variables relevant in explaining variations in the dependent variable about its mean value are omitted), then the coefficient estimates will be consistent and unbiased. However, since we are interested in making inferences about the significance of the estimated relationships, we correct for the heteroscedasticity by using White's (1980) heteroscedasticity-consistent standard errors, which are shown in parentheses in Table 1. We also allow for the dynamic structure of the sovereign yields by adding a lag of the dependent variable in each regression. The diagnostic checks on these modified models show no problems with autocorrelation $^{5}$. The ADF tests reject the null hypothesis that the errors contain a unit root in every case, as one would expect since all the independent variables are rates of change or unexpected changes. The RESET test shows no evidence of neglected nonlinearities in the residuals of any equation except that of Italy, where the null hypothesis that the linear functional form is appropriate is strongly rejected. The upshot of this result is that the residuals from the Italian regression are not white noise; in other words, there is still some "action" in the data that has not been explained by our model. Thus there might be other risk factors which affect the Italian yield, or the existing risk factors might affect it in a more complex (non-linear) fashion. The RESET test does not, however, give us any indication of the likely cause of the failure of the test, but the result reduces the attractiveness of Italy as a candidate for the risk-free rate.

\footnotetext{
${ }^{5}$ With the possible exception of Italy, where the autocorrelation test statistic is significant at the $5 \%$ level, but not the $1 \%$ level.
} 
Due to space constraints, none of the coefficient estimates or corresponding standard errors are shown, although all are available in an appendix upon request from the authors.

One problem in judging which sovereign short term rate is the best proxy for the risk free rate is that different variables are in different units of measurement, so that the raw size of the coefficient is not a reliable indicator of how important that variable is in determining the actual short term return. For instance, the French and Italian unexpected fiscal balance coefficients are -2.0608 and -2,608.3012 respectively, yet we cannot say that Italian unexpected fiscal balances have a greater influence on Italian short term returns than French unexpected fiscal balances have on French short term returns. To overcome this problem, we compute the elasticities of the coefficients; these are shown in Table one. Symbols denoting the level of significance refer to the coefficient estimates in the regressions.

\section{[table 1]}

These elasticities are unit free measures of response coefficients of short term returns to changes in independent variables. They are interpreted as the percentage response of the realized return to a percentage change in the independent variable. For instance, if the elasticity coefficient was 2 , this would mean that in response to a one percent change in the independent variable, there was a two percent change in the realized short return. As some of these coefficients were quite small, they have all been multiplied by 100 . Therefore the reported elasticity for German expected inflation is 28.7332, which means a one percent change in the rate of inflation would result in a 0.28 percent change in the short term T-bill return.

The first feature worthy of comment is that all the elasticity measures are quite small, particularly the elasticities of the fundamental factors. The largest elasticity on a risk factor is the German bond return elasticity, which says that in response to a one percent change in the world market returns, German short term rates increase by 0.08 percent. This suggest that while these short term returns have statistically significant responses to risk factors, the actual size of the response is small, so indeed the French, 
German, Italian and UK short term T-bill rates are all reasonable proxies for the risk free rate.

We are interested in choosing the best approximation for the risk free rate, however fine the distinction between it and the next best approximation may be. Since a true risk free rate should show no response, however small, to any risk factor, only the UK short term T-bill returns pass this criterion. Table one reveals that the sizes of the response coefficients are typically (but not always) the smallest.

The choice as the "next best" approximation is much more difficult. Nevertheless, we suggest that Germany is the next best candidate for two related reasons. First, Germany has a significant response to two risk factors, world bond returns and unexpected inflation, as opposed to three for both France and Italy. Second, we were forced to use the one year T-bill actual returns as the candidate for the German risk free rate as that was all that was available for a long enough time series to estimate (4). This is in contrast to France and Italy, (and the UK for that matter) where three month T-bill series were used as candidates for the risk free rate. To the extent that longer term instruments are more risky than short term instruments, using a longer term instrument for the German regression stacks the odds against Germany, yet the results compared to those of France and Italy are still slightly in favour of Germany. If we were to use German three month T-bills, we expect that the bond return coefficient would be more in line with those of France and Italy, as we see no other reason why the German bond return elasticity would be so much larger than the French and Italian bond elasticities other than the use of a longer term instrument for Germany. We also suggest that the unexpected inflation coefficient would be smaller as well since the impact on real returns of an unexpectedly higher inflation rate would have a larger impact on an investment fixed for a year rather than one fixed for only three months. Since Germany has recently made available a three month T-bill, we suggest that the rate on this instrument is the next best candidate for the risk free rate.

\subsection{The Benchmark Yield Curve}

The dependent variables that we attempt to explain are holding period returns above the sovereign's risk free yield for investments in 1-3, 3-5, 5-7, 7-10 and 10+ sovereign 
bonds for France, Germany, Italy and the UK, a total of 20 dependent variables in all. We explain these variables twice, using (4) and using (5), and we estimate these equations using the seemingly unrelated equation (SUR) technique. Since (5) requires estimates of several components of the constant, we use an iterated SUR technique in that instance.

The advantage of SUR is that the parameters (betas) are estimated by pooling time series and cross sectional (along a sovereign's yield curve) information allowing for more efficient estimation, yielding lower standard errors and increasing the statistical significance of results. Following Skinner (1995), we use the Breuch-Pagan (1980) test to determine whether SUR is in fact a more efficient technique than OLS ${ }^{6}$. For all four countries, we reject the null hypothesis that SUR gives no efficiency gain at the $1 \%$ level, clearly indicating that the SUR technique is appropriate. This result makes sense since it suggests that sovereign bond returns at different points along the yield curve for a given country in part move together. We actually run four sets of regressions, one for each sovereign, as we simultaneously estimate a structure of five regressions for each sovereign.

We estimate both (4) and (5) and compare the results in a likelihood ratio test to determine if the restrictions we impose on the constant in (5), that the constant is equal to $\sum_{k=1}^{K} \gamma_{i k} \lambda_{k}$, is valid 7 . This test is necessary since we would like to estimate the

\footnotetext{
${ }^{6}$ The Breuch-Pagan (1980) test calculates one half times the sum of the squared correlations of across equation residuals as estimated from OLS. This statistic is distributed as a Chi-Square with the number of degrees of freedom equal to one half times the number of off diagonal elements of the across equation residual correlation matrix, 10 each in the five equation structures examined here. If there is little across equation correlation, the across equation correlations in the residuals will be small so we reject in the case of large values. If we reject, this would imply large cross-equation correlations suggesting a SUR form is appropriate.

${ }^{7}$ Formally, this test statistic is [see Gallant(1987), page 367]

$$
\mathrm{L}=\mathrm{T}\left(\operatorname{Ln} \operatorname{det}\left(\mathrm{e}_{\mathrm{u}}\right)-\operatorname{Ln} \operatorname{det}\left(\mathrm{e}_{\mathrm{r}}\right)\right) \sim \chi^{2}(\mathrm{r})
$$

where $\mathrm{T}=$ number of observations, $\mathrm{e}_{\mathrm{u}}=$ unrestricted variance covariance matrix, [found by estimating (4)] $\mathrm{e}_{\mathrm{r}}=$ restricted variance covariance matrix [found by estimating (5)], $\mathrm{r}=$ the number of restrictions, equivalent to the number of fundamental risk premiums that we estimate. If these restrictions are binding, then the restricted variance covariance matrix would be significantly "different" from the unrestricted variance covariance matrix, so we reject the null for large values, implying that we should not impose the restrictions and estimate the risk premiums as we reject (5) as a valid model. We fail to reject the null even at the $20 \%$ level, so we conclude that (5) is a valid model. This test can be considered as the SUR equivalent of the standard F test.
} 
risk premiums $\lambda$ found by imposing the restriction. In common with Elton, Gruber and Blake (1995) we find that the ability of (5) to explain the dependent variables is as good as (4) so the restriction is valid. Accordingly, the results presented here represent estimation of (5) using the iterated SUR technique.

Table two reports estimates of the risk premiums for the five fundamental factors for France, Germany, Italy and the UK. We find that no sovereign has been assessed as requiring a risk premium by the market in recent years so that we cannot immediately rule out any of the four as candidates for the benchmark yield curve. This result suggests that all four sovereigns are of the highest credit quality and are legitimate candidates for the benchmark yield curve in a post-EMU world.

\section{[table 2]}

However, even though no sovereign has been assigned a risk premium in recent years, we can still judge one sovereign as a better benchmark than another by examining the significance and size of the risk factors. The idea is that the best benchmark is the one that not only has no significant risk premium, but also has no significant response to unexpected changes in the risk factors. Accordingly, at each maturity, the benchmark yield would be that sovereign that has the smallest elasticity for significant risk factors since this implies that the market demands a smaller adjustment in return for a one percent unexpected change in the risk factor.

Tables three to seven give the iterated SUR elasticities of the beta estimates for the market and fundamental factors 8 . These tables are constructed in the same manner, and report the results by maturity range. Beginning with Table three, we report the shortest maturity benchmark excess holding period return elasticity results for 1-3 years, then Table four reports the 3-5 year maturity results and so on. The first column reports the risk factor beta elasticity being estimated, and reading along the row reports the factor beta for France, Germany, Italy and the UK.

\footnotetext{
8 The same battery of diagnostics was applied to the residuals from these regressions as the earlier regressions used to determine the best proxy for the risk free rate, but none of the other diagnostic tests showed any significant evidence of further problems, and hence in the interests of brevity are not shown.
} 
In interpreting the results of these regressions, we must recognize that the dependent variable is the actual holding period return less the corresponding sovereign's proxy for the risk free yield. Therefore the sign of the factor betas reveals the market response to unexpected changes in this factor, a positive sign means that the market responds positively to an unexpected increase (unexpected good news) and a negative sign means the market responds to a negatively to an unexpected increase in the risk factor (unexpected bad news). No matter what the sign however, a significant beta reveals that source of risk is responded to by the market and hence our proxy for the benchmark yield curve will be the one with the fewest recognized (statistically significant) risk factors.

Unlike the earlier risk free rate analysis, this section examines holding period returns on longer term instruments, but we continue to use short term changes in the fundamental factors as explanatory variables. Therefore the question arises, how can we expect long term bond market securities to respond to short term trends? This question leads to a reinterpretation of two coefficients.

First, the response of long term bonds to changes in the short term expected inflation rate reveals the market's view of the sovereign's monetary authority credibility. A significantly negative coefficient suggests the market believes the sovereign may respond to the expected rate of inflation by raising future interest rates, so longer term bonds are sold, depressing long term bond prices. A significantly positive coefficient suggests the market believes the sovereign is not likely to respond to the expected rate of inflation by raising interest rates, so long term bond yields that incorporate the current rate of inflation will persist, making long term bonds attractive. If the market holds no strong views of the monetary authority's likely response to the expected rate of inflation, this coefficient will be statistically insignificant.

Second, the sign of the unexpected forward exchange rate coefficient reveals whether short or long term exchange rate effects dominate in the bond market. The short term effect of a depreciation in the value of a currency is negative since it reduces the international value of bond holdings and increases the likelihood of interest rate rises to protect the value of the currency. This would result in a negative unexpected 
foreign exchange response coefficient for all sovereigns but the UK since, as explained earlier, an increase in the foreign exchange rate for Sterling represents an appreciation. However, a longer term effect is to increase the international competitiveness of the domestic economy as the domestically produced goods are cheaper on the international market. This will feed through to GDP increases and will therefore improve the sovereign's ability to service debt so the unexpected foreign exchange response coefficient may also be positive for all sovereigns for this reason except for the UK.

Table three shows that for the 1-3 year maturity sector, the French and Italian yield curves dominate the German and British yield curves. While France and Italy have only two priced risk factors, Germany has four, while the UK has three. We suggest that France forms the benchmark at this point since France and Italy have unexpected GDP in common as a priced factor, and Italy's unexpected GDP's elasticity is more than four times larger than the corresponding elasticity for France.

[table 3]

In Table four, we see that the UK dominates all other candidates at the 3-5 year maturity sector since it has no priced risk factors, while Italy has only one, and France two. Therefore it appears that the Italian sovereign yield is the next best alternative as the benchmark yield for this maturity range.

\section{[table 4]}

Table Five studies the 5-7 year maturity sector. Here we have a three way tie between France, Italy and the UK as all have only one priced risk factor, none of which is in common. Therefore it is not clear which is the best benchmark for this maturity.

\section{[table 5]}

In Table Six, we notice that only Italy has no priced risk factor, while the UK and France have only one for the 7-10 maturity range. Therefore we suggest Italy forms the benchmark for this maturity range. It is not clear whether France or the UK forms the alternative benchmark yield curve since they both have one priced risk factor, neither of which is in common.

\section{[table 6]}

Finally, Table Seven reports the results for the long term maturity range, defined as 10 plus years. Here we see that only France has no priced risk factor, while the UK and 
Italy have one each. Again, we cannot definitively suggest the UK or Italy as the alternative benchmark since both have one risk factor not in common.

\section{[table 7]}

Overall, Tables Three to Seven reveal an interesting pattern. The pattern of significant factors for each sovereign is consistent with the view that qualifying under the Maastricht criteria for the EMU is good for the bond market. Abstracting from isolated instances where a factor is recognized by the market only once at a particular maturity we find that in general, unexpected income affects French and German, unexpected exchange rates affects German, unexpected fiscal balance affects Italian and equity market returns affects UK bond returns. Apparently the market is concerned about the inflationary impact of unexpected increases in income for France, but not for Germany. Instead, it appears that the market is more concerned about underutilized capacity for Germany since an increase in unexpected income is interpreted as good news, but an appreciation of the value of the mark, implying future reductions in exports, is treated as bad news. Meanwhile, the market responds favourably to improvements in Italy's fiscal balance. Interestingly, no fundamental factor for the UK is responded to by the market, implying either that the UK has no challenges to meet the Maastricht criteria, or the market does not believe that the UK will join the EMU so these factors do not matter. This view is consistent with Stone (1991), who claims that sovereign bond yields do not respond to macroeconomic factors unless they represent an adjustment to sovereign monetary or fiscal policy.

Examining our proxy for monetary authority credibility, we observe that Italy seems to have some problems in that regard as the expected inflation coefficient is significantly positive all along the yield curve except for the 10 plus maturity range. On the other hand we find evidence that Germany appears to have some monetary authority credibility as at the 10 plus maturity range, the expected inflation coefficient is significantly negative.

Conventional thinking would suggest that monetary authority credibility is a prerequisite for which sovereign forms the interest rate benchmark at a particular maturity range. Under this criterion, we would reject Italy as a candidate and look very favorably upon Germany as forming the benchmark yield curve. However, post EMU 
monetary policy decision making will no longer rest with individual sovereigns, but instead pass to a European wide institution. If EMU goes ahead with an independent pan-European monetary authority with at least as much credibility as, say, the current French monetary authorities, then this past national institutional framework is irrelevant and should not distract from considering the Italian yield curve as a candidate for forming the benchmark at particular maturity ranges. Our analysis assumes that EMU is successful in establishing a credible monetary authority, so we will suggest benchmarks based on priced risk factors only, and ignore existing levels of national monetary authority credibility.

Overall, we find that no one candidate yield curve dominates all of the others since different sovereign yield curves tend to have different significant risk factors. Accordingly, we are forced to examine the results separately by maturity sector. To summarise then, we suggest a composite yield curve as outlined in Table Eight.

\section{[table 8]}

It may appear surprising that Germany compares so unfavorably amongst the four candidates as a likely benchmark yield. We can gain some understanding why this might be so by examining the unexpected income coefficient for France and Germany. Here we notice that this risk factor is significant (i.e. recognised by the markets) for both sovereigns all along the yield curve with the exception of France at the 10 plus maturity range. In each case, France's coefficient is smaller than Germany's implying that the market views Germany as the riskier of the two. Also, notice that while France's coefficient is uniformly negative, Germany's coefficient is uniformly positive. As discussed earlier, a positive coefficient implies that the market believes that Germany has underutilized capacity, so unexpected income will translate into higher real income and improvements in their ability to service debt, while a corresponding unexpected increase in income for France is inflationary. It appears that the market believes that Germany has problems in absorbing the former East German productive capacity.

\section{Conclusions}

Applying a linear factor model to holding period returns on sovereign debt maturities of less than one year, 1-3 year, 3-5, 5-7, 7-10 and 10 plus years maturity for France, 
Germany, Italy and the UK, we were able to examine what would be a reasonable proxy for the risk free rate and benchmark yield curve in an EMU world. We found that three month UK Treasury bills would be the best proxy for the risk free rate, followed by three month German Treasury Bills. The benchmark yield curve would be a composite yield curve consisting of French, Italian and British sovereign bonds at different points along the yield curve. A surprising result is that German bonds seem dominated by the other three candidates all along the yield curve, possibly because the market believes Germany has an unresolved challenge to integrate the former East German productive capacity into its national economy.

\section{References}

Bera, A.K. and C.M. Jarque (1981) "An Efficient Large-Sample Test for Normality of Observations and Regression Residuals" Australian National University Working Papers in Econometrics 40, Canberra

Box G. and G. Jenkins (1976) Time Series Analysis: Forecasting and Control Revised Edition, Holden-Day, San Francisco.

Breuch, T. and A. Pagan (1980) "The Lagrange Multiplier Test and its Application to Model Specification in Econometrics" Review of Econometric Studies 47, 239-254.

Cantor R., and F. Packer (1996) "Determinants and Impact of Sovereign Credit Ratings" Federal Reserve Board of New York Economic Policy Review October, 3753.

Chen, N., R. Roll and S. Ross (1986) "Economic Forces and the Stock Market" Journal of Business 59, 383-404.

Cosset, J., M. Daouas, O. Kettani and M. Oral (1993) "Replicating Country Risk Ratings" Journal of Multinational Financial Management 3(1), 1-29.

Cosset, J. and J. Roy (1991) "The Determinants of Country Risk Ratings" Journal of International Business Studies 22(2), 135-142.

Dallas, G. and I. Mackintosh (1997) "The Impact of EMU on Bonds and Credit" The European Bond Markets, McGraw-Hill, $6^{\text {th }}$ edition, Editor, Nick Battley.

Dickey, D.A. and W.A. Fuller (1979) Distribution of Estimators for Time Series Regressions with a Unit Root Journal of the American Statistical Association 74, 427431

Elton, E., M. Gruber and C. Blake (1995) "Fundamental Economic Variables, Expected Returns, and Bond Fund Performance" Journal of Finance 50(4), 12291255. 
Engle, R.F. (1982) Autoregressive Conditional Heteroskedasticity with Estimates of the Variance of United Kingdom Inflation Econometrica 50(4), 987-1007

Fuller, W.A. (1976) Introduction to Statistical Time Series Wiley, N.Y.

Hogeweg, G., (1996) "General Aspects of European Monetary Integration" http://www.Euro-activities.be/1996_3/hogeweg.htm

Jarrow, R. (1978) "The relationship Between Yield, Risk and Return of Corporate Bonds" Journal of Finance 33(4), 1235-1240.

Gallant, A. (1987) Nonlinear Statistical Methods John Wiley and Sons, New York.

Ljung, G.M. and G.E.P. Box (1978) On a Measure of Lack of Fit in Time Series Models Biometrika 65(2), 297-303

Ramsey, J.B. (1969) Tests for Specification Errors in Classical Linear Least-Squares Regression Analysis Journal of the Royal Statistical Society B 31(2), 350-371

Rao, R. (1982) "The Impact of Yield Changes on the Systematic Risk of Bonds" Journal of Financial and Quantitative Analysis 17(1) 115-127.

Rockerbie, D. (1993) "Explaining Interest Rate Spreads on Sovereign Eurodollar Loans: LDCs Verses DCs, 1978-84” Applied Economics 25 (5) 609-616.

Skinner, F. (1995) "Bond Yields, Taxes and the Dimensions of Default Risk" Financial Review 30(4), 739-761

Stone, M. (1991) "Are Sovereign Debt Secondary Markets Returns Sensitive to Macroeconomic Fundamentals? Journal of International Money and Finance 10 (sup), S100-S122.

White, H. (1980) "Heteroscedasticity: Consistent Variance Matrix Estimator and A Direct Test for Heteroscedasticity" Econometrica 48, 817-838. 
Table One: Coefficient Elasticities-Treasury Bills

\begin{tabular}{ccccc}
\hline Coefficient & France & Germany & Italy & UK \\
\hline Equity Return & $-1.5208+$ & -1.0056 & -0.7916 & 0.8407 \\
Bond Return & $2.8408+$ & $8.0019+$ & 1.3169 & 0.5595 \\
Expected Inflation & $20.7052+$ & $28.7332+$ & $19.9920 \#$ & $28.1217+$ \\
Unexpected Inflation & -0.1132 & $-0.1344^{*}$ & -0.0543 & -0.0080 \\
Unexpected GDP & 0.0070 & -0.0333 & 0.0604 & -0.0015 \\
Unexpected Fiscal Balance & $-0.0152^{*}$ & -0.0224 & $-0.1973 *$ & -0.0015 \\
Unexpected Income & -0.0036 & 0.1430 & 0.1056 & 0.1616 \\
Unexpected Exchange Rate & -0.0256 & 0.1041 & 0.0029 & 0.0375 \\
\hline
\end{tabular}

+ significant at the $1 \%$ level, * significant at the 5\% level, \# significant at the $10 \%$ level.

Table Two: Regression Results for Risk Premiums

\begin{tabular}{ccccc}
\hline Coefficient & France & Germany & Italy & UK \\
\hline Unexpected Inflation Risk & -1.8972 & -0.1682 & 0.7154 & 1.0024 \\
Premium & $(3.5309)$ & $(1.0753)$ & $(0.8373)$ & $(1.5022)$ \\
Unexpected GDP Risk & 8.7122 & -3.9392 & -27.6665 & 3.2226 \\
Premium & $(32.8000)$ & $(9.2049)$ & $(24.6694)$ & $(64.9938)$ \\
Unexpected Fiscal Balance & -1.4857 & 0.0187 & -0.0002 & 0.5961 \\
Risk Premium & $(2.2859)$ & $(0.4295)$ & $(0.0006)$ & $(2.6830)$ \\
Unexpected Income Risk & 0.0306 & -0.0662 & -0.0375 & 0.0838 \\
Premium & $(0.2371)$ & $(0.3863)$ & $(0.1528)$ & $(0.4113)$ \\
Unexpected Exchange Rate & 0.4462 & 0.0977 & -21.7616 & 0.0770 \\
Risk Premium & $(1.2160)$ & $(0.1895)$ & $(205.8463)$ & $(0.2079)$ \\
\hline
\end{tabular}

Note: Standard errors in parentheses.

Table Three: Elasticity Results for 1-3 Years to Maturity

\begin{tabular}{ccccc}
\hline Coefficient & France & Germany & Italy & UK \\
\hline Equity Return & -0.0390 & $-0.6425^{*}$ & -0.0992 & $-0.3695^{*}$ \\
Bond Return & 0.0819 & -0.0064 & 0.0063 & 0.0171 \\
Expected Inflation & 2.9079 & -3.7773 & $2.6196 \#$ & 2.3088 \\
Unexpected Inflation & 0.0049 & $0.2772 \#$ & 0.0373 & 0.0959 \\
Unexpected GDP & $0.0055 \#$ & -0.0058 & $0.0241 \mathrm{x}$ & -0.0241 \\
Unexpected Fiscal Balance & -0.0006 & -0.0022 & $0.0116^{*}$ & 0.0014 \\
Unexpected Income & $-0.0614^{*}$ & $0.2035^{*}$ & -0.0185 & $-0.3221^{*}$ \\
Unexpected Exchange Rate & 0.0157 & $-0.0437^{*}$ & -0.0017 & $-0.0556^{*}$ \\
\hline
\end{tabular}

Notes: + significant at the $1 \%$ level, * significant at the $5 \%$ level, \# significant at the $10 \%$ level, $\mathrm{x}$ significant at the $11 \%$ level.

Table Four: Elasticity Results for 3-5 Years to Maturity

\begin{tabular}{ccccc}
\hline Coefficient & France & Germany & Italy & UK \\
\hline Equity Return & -0.1158 & $-0.3462 \#$ & -0.1134 & -0.3788 \\
Bond Return & 0.1220 & 0.0639 & 0.0087 & 0.0621 \\
Expected Inflation & 3.8474 & -2.0159 & $3.1402^{*}$ & 1.7132 \\
Unexpected Inflation & 0.0035 & -0.0714 & 0.0766 & 0.0693 \\
Unexpected GDP & $0.0055 \mathrm{x}$ & -0.0068 & 0.0239 & -0.0400 \\
Unexpected Fiscal Balance & -0.0011 & -0.0046 & $0.0012 \#$ & -0.0014 \\
Unexpected Income & $-0.0716^{*}$ & $0.1260 \#$ & -0.0117 & -0.2628 \\
Unexpected Exchange Rate & 0.0185 & $-0.0346^{*}$ & 0.0009 & 0.0495 \\
\hline
\end{tabular}

Notes: + significant at the $1 \%$ level, * significant at the $5 \%$ level, \# significant at the $10 \%$ level, $\mathrm{x}$ significant at the $11 \%$ level. 
Table Five: Elasticity Results for 5-7 Years to Maturity

\begin{tabular}{ccccc}
\hline Coefficient & France & Germany & Italy & UK \\
\hline Equity Return & -0.1349 & -0.3069 & -0.1274 & $-0.4632 \#$ \\
Bond Return & 0.1255 & 0.0612 & $0.0089 \#$ & 0.07531 \\
Expected Inflation & 4.0892 & -2.2781 & $2.6701 \#$ & 0.7704 \\
Unexpected Inflation & 0.0049 & -0.0138 & 0.0873 & 0.1120 \\
Unexpected GDP & 0.0054 & -0.0086 & 0.0152 & -0.0404 \\
Unexpected Fiscal Balance & -0.0012 & -0.0024 & 0.0078 & -0.0013 \\
Unexpected Income & $-0.0662 \#$ & $1.3425^{*}$ & -0.0243 & -0.2557 \\
Unexpected Exchange Rate & 0.0178 & $-0.0374^{*}$ & 0.0089 & -0.0505 \\
\hline
\end{tabular}

Notes: + significant at the $1 \%$ level, * significant at the $5 \%$ level, \# significant at the $10 \%$ level.

Table Six: Elasticity Results for 7-10 Years to Maturity

\begin{tabular}{ccccc}
\hline Coefficient & France & Germany & Italy & UK \\
\hline Equity Return & -0.1918 & -0.3281 & -0.1074 & $-0.3964 \mathrm{x}$ \\
Bond Return & 0.1442 & 0.0454 & 0.0083 & 0.0600 \\
Expected Inflation & 4.0894 & -2.7793 & $2.6437 \#$ & 0.1496 \\
Unexpected Inflation & 0.0074 & 0.0394 & 0.0581 & 0.1240 \\
Unexpected GDP & 0.0058 & -0.0083 & 0.0184 & -0.0397 \\
Unexpected Fiscal Balance & -0.0013 & -0.0007 & 0.0089 & -0.0011 \\
Unexpected Income & $-0.0739 \#$ & $0.1565^{*}$ & 0.0024 & -0.2294 \\
Unexpected Exchange Rate & 0.0202 & $-0.0395^{*}$ & 0.0154 & -0.0436 \\
\hline
\end{tabular}

Notes: + significant at the $1 \%$ level, $*$ significant at the $5 \%$ level, \# significant at the $10 \%$ level, $\mathrm{x}$ significant at the $11 \%$ level.

Table Seven: Elasticity Results for 10+ Years to Maturity

\begin{tabular}{ccccc}
\hline Coefficient & France & Germany & Italy & UK \\
\hline Equity Return & -0.2255 & -0.3187 & -0.1553 & -0.2877 \\
Bond Return & 0.1164 & 0.0378 & 0.0125 & 0.0456 \\
Expected Inflation & 3.1177 & $-3.9967 \#$ & 3.6159 & -1.5587 \\
Unexpected Inflation & 0.0075 & 0.03296 & 0.1128 & 0.1392 \\
Unexpected GDP & 0.0063 & -0.0091 & 0.0202 & $-0.0407 \#$ \\
Unexpected Fiscal Balance & -0.0010 & -0.0043 & $0.0153 \mathrm{x}$ & -0.0010 \\
Unexpected Income & -0.0569 & $0.2332+$ & 0.0307 & -0.1902 \\
Unexpected Exchange Rate & 0.0216 & $-0.0508+$ & 0.0245 & -0.0268 \\
\hline
\end{tabular}

Notes: + significant at the $1 \%$ level, * significant at the $5 \%$ level, \# significant at the $10 \%$ level, $\mathrm{x}$ significant at the $11 \%$ level.

Table Eight: Composite Yield Curve

\begin{tabular}{lll}
\hline Maturity Range & Sovereign & Alternative \\
\hline risk free $(0-1$ year $)$ & UK & Germany \\
$1-3$ years & France & Italy \\
$3-5$ years & UK & Italy \\
$5-7$ years & France/Italy/UK & - \\
$7-10$ years & Italy & France/UK \\
10 plus years & France & Italy/UK \\
\hline
\end{tabular}

